\title{
Sofosbuvir vs. Combination of Pegylated Interferon and Ribavirin; How Much Shall Pay for Iranian Patients?
}

\author{
Mohamad Amin Pourhoseingholi ${ }^{1}$; Sara Ashtari ${ }^{1}$; Seyed Moayed Alavian ${ }^{2, *}$ \\ ${ }^{1}$ Gastroenterology and Liver Diseases Research Center, Shahid Beheshti University of Medical Sciences, Tehran, IR Iran \\ ${ }^{2}$ Middle East Liver Diseases Center (MELD), Tehran, IR Iran \\ *Corresponding Author: Seyed Moayed Alavian, Middle East Liver Diseases Center (MELD), Tehran, IR Iran. Tel: +98-9128938931, E-mail: alavian@thc.ir
}

Received: November 22, 2014; Accepted: November 23, 2014

Keywords:Hepatitis C; Therapy; Sofosbuvir; Cost; Peginterferon

HCV has still a significant impact on health care system and its burden is expected to increase over the next decade due to morbidity, mortality and liver transplantation (1). It can also place a high socioeconomic burden on the individuals and the society, becoming chronic and impose enormous costs both on the patients as well as on health system (2). So this is obvious that the health costs of such chronic disease are the concern of many health policy makers. Measuring the economic burden of HCV care is effectiveness to better understand and evaluate various intervention programs in the country (3).

The current available treatment for chronic HCV hepatitis is the combination of pegylated interferon (PEG-IFN) and ribavirin (RBV), this combination therapy has become a standard around the world and in Iran, too (4), However the response rats differ among patients with different genotypes; while about $80 \%$ of patients with genotypes 2 and 3 infection can be cured, the sustained virologic response (SVR) is only 40-50\% in genotype 1 (3, 5). Reaching SVR for these patients not only prevents cirrhosis or liver failure, but also improve a patient's quality of life. Recently a new direct-acting antivirals (DAAs), called sofosbuvir (SOF), arrived, which have shown SVR rates over $90 \%$ across genotypes, higher than the current treatments $(6,7)$. Besides, SOF treatment's duration is shorter than their counterpart. Studies in western countries, using decision-analytic Markov model simulation, showed that SOF + PEG-IFN/RBV yields more favorable future health and economic outcomes across all levels of treatment experience, specifically SOF treatment may be a cost-effective alternative to genotype 1 patients (depending on pricing) $(8,9)$. But there is still question regarding its budget constraints. In absence of any Iranian clinical trial on efficacy of SOF and its cost for Iranian patients, we tried to estimate the average cost of SOF treatment, using our recent results on HCV medical care costs and other similar studies on SOF costs. Our recent study on direct medical care costs associated with patients diagnosed with chronic HCV, indicated that average direct medical costs for the courses treated with peg-interferon plus ribavirin (PEG-RBV) was 20,010 PPP\$ and this cost increases for SVR, up to 39,094 PPP\$ (Physician visit, Laboratory tests, Hospitalization, etc were included) (3). A French study calculated an average cost of SOF treatment $67,291 €$ (including all genotypes, without other costs like as Physician visits, etc.) (10). Incorporating with our cost analysis, consider that the duration of treatment reduces from 24 weeks to 12 weeks, converting all price units to Purchasing Power Parity Dollar (PPP\$) (3), and suppose that other cost (including Physician visit, Laboratory tests, Hospitalization) are fixed, the average cost of a SOF treatment course with combination of (PEG-RBV) for Iranian patient with HCV, would be expected to 266,424 PPP\$ (which almost increases up to $1200 \%$ ). This cost is not so different across genotypes, for example in genotype 3, it is estimated to be 262,575 PPP\$.

The price of SOF in high-income countries is expected to be very high and this price would be higher for most patients in developing countries. In Iranian patients, combination therapy has 70-80\% SVR (not for difficult to treat patients), on the other hand, the efficacy of SOF in clinical trials of over 90\% SVR was available only for the group of non-cirrhotic patients without differentiating stage of fibrosis. In absence of any clinical trials on Iranian patient's SVR rate for SOF and its cost-effectiveness, the question under critics is that; how much shall spent and by who (patients or insurance system) to increasing $10-20 \%$ SVR, with changing the combination therapy?

\section{References}

1. Alavian SM. Hepatitis C virus infection: Epidemiology, risk factors and prevention strategies in public health in IR IRAN. Gastro Hepat. 2009;3(1):5-14.

2. Kanwal F, Farid M, Martin P, Chen G, Gralnek IM, Dulai GS, et al. Treatment alternatives for hepatitis B cirrhosis: a cost-effective-

Copyright (C) 2014, Kowsar Corp. This is an open-access article distributed under the terms of the Creative Commons Attribution-NonCommercial 4.0 International License (http://creativecommons.org/licenses/by-nc/4.0/) which permits copy and redistribute the material just in noncommercial usages, provided the original work is properly cited. 
ness analysis. Am J Gastroenterol. 2006;101(9):2076-89.

3. Ashtari S, Vahedi M, Pourhoseingholi MA, Karkhane M, Kimiia Z, Pourhoseingholi A, et al. Direct medical care costs associated with patients diagnosed with chronic HCV. Hepat Mon. 2013;13(5).

4. Alavian SM, Mirmomen S, Lankarani KB, Adibi P, Merat S. What is the optimal treatment? Hepat Mon. 2004;4(4):5.

5. Sargolzaee Aval F, Behnaz N, Raoufy MR, Alavian SM. Predicting the outcomes of combination therapy in patients with chronic hepatitis C using artificial neural network. Hepat Mon. 2014;14(6).

6. Kowdley KV, Lawitz E, Crespo I, Hassanein T, Davis MN, DeMicco $\mathrm{M}$, et al. Sofosbuvir with pegylated interferon alfa-2a and ribavirin for treatment-naive patients with hepatitis $C$ genotype- 1 infection (ATOMIC): an open-label, randomised, multicentre phase
2 trial. Lancet. 2013;381(9883):2100-7.

7. Alavian SM. Sofosbuvir has come out of the magic box. Hepat Mon. 2013;13(12)

8. Petta S, Cabibbo G, Enea M, Macaluso FS, Plaia A, Bruno R, et al. Cost-effectiveness of sofosbuvir-based triple therapy for untreated patients with genotype 1 chronic hepatitis C. Hepatology. 2014;59(5):1692-705.

9. Saab S, Gordon SC, Park H, Sulkowski M, Ahmed A, Younossi Z. Cost-effectiveness analysis of sofosbuvir plus peginterferon/ ribavirin in the treatment of chronic hepatitis $C$ virus genotype 1 infection. Aliment Pharmacol Ther. 2014;40(6):657-75.

10. Leleu H, Blachier M, Rosa I. Cost-effectiveness of sofosbuvir in the treatment of patients with hepatitis C.J Viral Hepat. 2014. 